\title{
PENINGKATAN KETERAMPILAN GURU MA AL-AZIZIYAH PUTERI KAPEK, GUNUNGSARI DALAM MENGEMBANGKAN INSTRUMEN ASESMEN SIKAP DAN KETERAMPILAN HASIL BELAJAR
}

\author{
D. Setiadi*1, Sudirman Wilian ${ }^{2}$, I Nyoman Sridana ${ }^{3}$ \\ ${ }^{1}$ Pendidikan Biologi, FIKP, Universitas Mataram \\ ${ }^{2}$ Program Studi Magister Administrasi Pendidikan, Program Pascasarjana, Universitas Mataram \\ ${ }^{13}$ Program Studi Pendidikan Matematika, FKIP, Universitas Mataram \\ *e-mail: setiadi_dadi@unram.ac.id ${ }^{1}$
}

\begin{abstract}
The purpose of this service is to increase the capability of teachers at MA Al Aziziyah Putri in developing the ability to compose instruments to measure the attitudes and skills of students. The method used in this community service is through training or workshops that are more based on direct practice in compiling instruments that refer to the juridical basis, study of literature, and analysis of teacher needs in the MA Al Aziziyah Puteri environment related to the preparation of attitudes and skills assessment instruments. The implementation of the service is carried out in the following stages: Literature study, analyzing teacher needs, measuring teacher initial abilities, designing training curriculum, training implementation in the form of theoretical studies, practice analysis of skills and attitudes in curriculum documents and preparation of skills and attitude assessment instruments. Monitoring and guidance in the field, Evaluation of Workshop Implementation Results and, Preparation of Service Reports. The population is all female MA Al Aziziyah teachers, the sample used is 40 teachers. The results showed that all participants understood and were skilled in designing instruments for assessing attitudes and skills according to the basic competencies of KD 3 and KD 4 contained in the MA curriculum. However, workshop participants still need training in the preparation of these instruments, especially in determining indicators of attitudes, skills to compiling accurate instruments according to the bill.
\end{abstract}

Keywords: teacher MA skills; assessment instruments; attitudes and skills; learning outcomes

\begin{abstract}
Abstrak
Tujuan pengabdian ini untuk meningkatkan kapabilitas guru di MA Al Aziziyah puteri dalam mengembangkan kemampuan menyusun instrumen untuk mengukur sikap dan keterampilan peserta didik. Metode yang digunakan dalam pengabdian kepada masyarakat ini adalah melalui pelatihan atau workshop yang lebih berbasis pada praktek langsung menyusun instrumen yang mengacu pada dasar yuridis, studi literatur, dan analisis kebutuhan guru di lingkungan MA Al Aziziyah Puteri terkait dengan penyusunan instrumen penilaian sikap dan keterampilan. Pelaksanaan pengabdian dilakukan dengan tahapan sebagai berikut : Studi literatur, menganalisis kebutuhan guru, Pengukuran Kemampuan Awal Guru, Mendisain Kurikulum Pelatihan, Pelaksanaan Pelatihan berupa kajian teori, Praktek Analisis tagihan keterampilan dan sikap pada dokumen kurikulum dan Penyusunan instrument asesmen keterampilan dan sikap. Pemantauan dan bimbingan di lapangan, Evaluasi Hasil Pelaksanaan Workshop dan, Penyusunan Laporan Pengabdian., Populasi adalah semua guru MA Al Aziziyah puteri, sampel yang digunakan sebanyak 40 guru. Hasil menunjukan semua peserta sudah mamahami dan terampil dalam mendisain instrumen untuk penilaian sikap dan keterampilan sesuai dengan tagihan pada kompetensi dasar dari KD 3 dan KD 4 yang terdapat pada kurikulum MA. Namun demikian para peserta wrokshop masih memerlukan latihan penyusunan instrumen tersebut khususnya dalam penentuan indikator sikap, keterampilan sampai menyusun instrumennya yang akurat sesuai dengan tagihan
\end{abstract}

Kata kunci: keterampilan guru ma; instrumen asesmen; sikap dan keterampilan; hasil belajar

\section{PENDAHULUAN}

Lebih sesuai dengan kebutuhan masyarakat dan diharapkan lulusan mampu menghadapi tantangan kehidupan di masa mendatang. Seperti halnya kurikulum nasional bertujuan untuk mempersiapkan manusia Indonesia agar memiliki kemampuan hidup sebagai pribadi dan warga negara yang beriman, produktif, kreatif, inovatif, dan afektif serta mampu berkontribusi pada kehidupan bermasyarakat, berbangsa, bernegara, dan peradaban dunia (Peraturan Menteri 
Pendidikan dan Kebudayaan Republik Indonesia Nomor 66 Tahun 2013), dan untuk mengembangkan potensi berpikir reflektif peserta didik untuk penyelesaian masalah sosial di masyarakat, serta untuk membangun kehidupan masyarakat demokratis yang lebih baik (Peraturan Menteri Pendidikan dan Kebudayaan Nomor 69 Tahun 2013). Perubahan kurikulum di madrasah akan menuntut guru untuk mampu menginterpretasi tagihan, menyusun rencana pembelajaran dan mengimplementasikannya termasuk asesmen hasil belajar khususnya sikap dan keterampilan.

Berdasarkan hasil studi pendahuluan di lapangan pada para guru MA Al Aziziyah di pesantren Kapek belum mengimplementasikan kurikulum nasional secra baik dan komprehnsif setelah. Hal tersebut merupakan masalah yang dihadapi oleh madarash secara umum dan para guru pengmu mata pelajaran khususnya. Selain itu para guru Madrasah Al Aziziyah Puteri di lingkungan pesantren Kapek masih belum memiliki pemahaman dan keterampilan yang baik khususnya dalam penyusunan instrumen penilaian keterampilan dan sikap secara komprehensif termasuk hal teknis bagaimana mengembangkan dan melaksanakan penilaian sikap dan keterampilan sesuai kurikulum nasional seperti kompetensi dasar 2 dan 4, termasuk juga pengembangan prosesnya sehingga sikap sosial, dan keterampilan peserta didik bisa di ases. Tagihan tersebut menurut para guru merupakan hal yang baru yang harus dimilki untuk bisa mengimplementasikan kurikulum nasional secara baik dan benar, sehingga tujuan dari kurikulum tersebut diharapkan bisa dicapai. Selain itu, guru-guru yang mengimplementasikan kurikulum nasional harus mampu menginterpretasi apa yang ditagih oleh standar isi kurikulum khususnya yang menyangkut 2 komptetensi yaitu sikap dan keterampilan. Jika salah dalam menginterpretasi tagihan maka proses pembelajaran dan asesmen tidak akan sesuai dan bisa mencapai tujuan kurikulum nasional. Hal lain, keterampilan guru dalam mengimplementasikan kurikulum nasional tidak hanya harus terampil dalam mengembangkan pengetahuan tetapi juga keterampilan dan sikap serta instrument asesmennya. Oleh karena itu, guru harus memiliki juga kemampuan dalam menganalisis dan mengembangkan proses pembelajaran sesuai dengan bidang keahlian mata pelajaran guru masing-masing.

Kemampuan menyusun instrument penilaian sikap dan keterampilan kurikulum nasional merupakan satu keterampilan yang harus dimiliki guru agar tidak salah dalam mengartikan tagihan kurikulum termasuk juga prosesnya dan penilainnya yang harus dilaksanakan. Selain itu, guru harus terampil dalam mengases/mengukur kemampuan keterampilan dan sikap, serta harus piawai dalam mendisain perencanaan dan mendisain pengalaman belajar yang paling sesuai dengan tagihan kurikulum, sehingga siswa bisa belajar dan dapat mengembangkan pengetahuan, sikap dan keterampilan dengan baik sesuai dengan tuntutan kurikulum nasional yang berbasis pada model pembelajaran problem based learning, project base learning dan discovery learning (Peraturan Menteri Pendidikan dan Kebudayaan Republik Indonesia Nomor 65 Tahun 2013).

Menurut Peraturan Menteri Pendidikan dan Kebudayaan Republik Indonesia Nomor 81a Tahun 2013 bahwa kurikulum nasional dikembangkan agar memungkinkan penyesuaian program pendidikan pada satuan pendidikan dengan kekhasan potensi peserta didik; dan yang memungkinkan potensi diri (afektif, kognitif, psikomotor) bisa berkembang secara optimal. Sejalan dengan itu, kurikulum disusun dengan memperhatikan potensi, tingkat perkembangan, minat, kecerdasan intelektual, emosional, sosial, spritual, dan kinestetik peserta didik. Juga proses pembelajaran harus mengembangkan lima pengalaman belajar pokok yaitu: mengamati; menanya; mengumpulkan informasi; mengasosiasi; dan mengkomunikasikan. Proses pembelajaran sepenuhnya diarahkan pada pengembangan ketiga ranah tersebut secara utuh/holistik, artinya pengembangan ranah yang satu tidak bisa dipisahkan dengan ranah lainnya. Dengan demikian proses pembelajaran secara utuh bisa melahirkan kualitas pribadi yang mencerminkan keutuhan penguasaan sikap, pengetahuan, dan keterampilan. (Peraturan Menteri Pendidikan dan Kebudayaan Republik Indonesia Nomor 65 Tahun 2013). Selain itu, kurikulum nasional dirancang dengan karakteristik-karakteristik tertentu, diantaranya mengembangkan keseimbangan antara pengembangan sikap spiritual dan sosial, rasa ingin tahu, kreativitas, kerja 
sama dengan kemampuan intelektual dan psikomotorik (Peraturan Menteri Pendidikan dan Kebudayaan Republik Indonesia Nomor 66 Tahun 2013). Kurikulum dikembangkan dengan memberikan kesempatan kepada peserta didik untuk mengembangkan perbedaan dalam kemampuan dan minat. Atas dasar prinsip perbedaan kemampuan individual peserta didik tersebut, kurikulum nasional memberikan kesempatan kepada peserta didik untuk memiliki tingkat penguasaan di atas standar yang telah ditentukan secara nasional (dalam sikap, keterampilan dan pengetahuan). (Kementerian Pendidikan dan Kebudayaan, 2012)

Dalam pengembangan standar proses dan evaluasi kurikulum nasional bertujuan untuk mewujudkan tujuan pendidikan nasional (Peraturan Pemerintah Republik Indonesia Nomor 32 Tahun 2013; Undang-Undang Republik Indonesia Nomor 20 Tahun 2003 ). Standar konten tersebut berupa Kompetensi Dasar mencakup sikap spiritual, sikap sosial, pengetahuan, dan keterampilan dalam muatan mata pelajaran. Kompetensi dasar dikembangkan didasarkan pada prinsip akumulatif, saling memperkuat (reinforced) dan memperkaya (enriched) antar mata pelajaran dan jenjang pendidikan (organisasi horizontal dan vertikal) (Peraturan Menteri Pendidikan dan Kebudayaan Republik Indonesia Nomor 66 Tahun 2013). Pertama, sikap spiritual yang terkait dengan tujuan pendidikan nasional membentuk peserta didik yang beriman dan bertakwa. Kedua, sikap sosial yang terkait dengan tujuan pendidikan nasional membentuk peserta didik yang berakhlak mulia, mandiri, demokratis, dan bertanggung jawab (Kementerian Pendidikan dan Kebudayaan, 2013). Pengembangan konten akan terkait dengan proses dan asesmen khususnya sikap dan keterampilan yang masih dianggap sulit oleh guru MA Al Aziziyah puteri Kapek. Oleh karena itu guru harus meningkatkan pemahaman dan keterampilan serta teknik asesmen khusunya dalam ranah sikap dan keterampilan.

\section{METODE}

Metode yang digunakan dalam pengabdian kepada masyarakat ini adalah melalui pelatihan atau workshop yang lebih berbasis pada praktek langsung menyusun instrumen yang mengacu pada dasar yuridis, studi literatur, dan analisis kebutuhan guru di lingkungan MA Al Aziziyah Puteri terkait dengan penyusunan instrumen penilaian sikap dan keterampilan. Pelaksanaan pengabdian dilakukan dengan tahapan sebagai berikut : Studi literatur, menganalisis kebutuhan guru, Pengukuran Kemampuan Awal Guru, Mendisain Kurikulum Pelatihan, Pelaksanaan Pelatihan berupa kajian teori, Praktek Analisis tagihan keterampilan dan sikap pada dokumen kurikulum dan Penyusunan instrument asesmen keterampilan dan sikap. Pemantauan dan bimbingan di lapangan, Evaluasi Hasil Pelaksanaan Workshop dan, Penyusunan Laporan Pengabdian., Populasi adalah semua guru di lingkungan MA Al Aziziyah Puteri, sampel yang digunakan sebanyak 40 guru. Pengumpulan data dilakukan dengan mengevaluasi produk berupa perangkat pembelajaran hasil kegiatan workshop. Data dianalisis deskriptif kualitatif.

\section{HASIL DAN PEMBAHASAN}

Pemahaman guru MA Al Aziziyah Puteri Kapek Gunungsari berhubungan dengan kurikulum nasional/K13, kompetensi dasar sikap spiritual dan sosial dan keterampilan kurikulum 2013 menunjukan pemahaman yang jauh lebih baik dibanding dengan sebelumnya, hal ini memberikan rasa optimisme pada yang bersangkutan untuk bisa menyusun instrumen penilaian sikap dan keterampilan termasuk melaksanakan dan menganalisisnya sesuai dengan kebijakan dan peraturan yang berlaku. untuk lebih meningkatkan aspek keterampilan tersebut hendaknya guru lebih intensif membimbing agar siswa lebih terbiasa belajar sendiri menemukan konsepkonsep, prinsip-prinsip ilmiah, serta mengembangkan kreativitas dalam pemecahan masalahmasalah sains (Juhji. 2016). Dengan demikian guru-guru di MA Al Aziziyah Puteri Kapek Gunungsari akan mampu menyusun rencana pembelajaran sesuai dengan tagihan kompetensi dasar khususnya untuk instrumen penilaian sikap dan keterampilan termasuk pengalaman belajar peserta didik.

Selain itu guru telah memiliki keterampilan dalam menganalisis tagihan kurikulum khususnya kompetensi inti dan dasar 2 dan 4 . Juga kompetensi dasar 4 duru sudah bisa 
menjabarkan menjadi sejumlah indikator pencapaian kompetensi, sehingga para guru tidak mengalami kesulitan ketika mendisan indikator pencapain kompetensi pada saat menysusun rencana pembelajaran tingkat MA. Guru ketika menyusun instrumen asesmen akan sesuai dengan tagihan yang ada pada dokumen kurikulum yaitu kompetensi dasar dari semua kompetensi inti. Dalam konteks evaluasi sikap terdapat 4 model evaluasi yang dapat diterapkan guru dalam mengevaluasi sikap siswa seperti: (1) Evaluasi mandiri; (2) Observasi guru; (3) Peer assessment; dan (4) Jurnal harian. (Darmansyah. 2014)

Berhubungan dengan interpretasi tagihan isi kurikulum 2013 hasil revisi pada tahun 2016 mata pelajaran di MA, guru sudah terampil dalam mengembangkan isntrumen, hal ini menunjukan bahwa guru akan bisa mendisain perencanaan dan tujuan pembelajaran sesuai dengan mata pelajaran yang diampu guru yang bisa melebihi tagihan minimal standar nasional. Dengan demikian besar harapan akan bisa melaksanankan proses pembelajaran yang lebih bermutu sehingga bisa mencapai tujuan kurikulum 2013 terutama yang mencakup aspek sikap dan keterampilan secara maksimal.

Guru telah memiliki keterampilan yang lebih baik dalam mendesain rencana program pembelajaran yang sesuai dengan tuntutan kurikulum termasuk asesmen utnuk sikap dan keterampilan. Hal tersebut telah memenuhi tagihan sesuai dengan permendikbud standar proses dan evalausi yang berlaku tahun 2016. Dengan demikian keterampilan dalam menyusun rencana pembelajaran akan terkait dengan implementasinya dan akan memiliki kemungkinan baik dalam implementasi pembelajaran dan evalausinya. Namun demikian dalam implementasi pembelajaran masih perlu pemahaman terkait dengan semua aspek atau sub sistem pembelajaran yang terlibat dalam proses pembelajaran yang harus dipersiapkan secara maskimal sebelumnya agar proses pembelajaran berbasis pada siswa aktif bisa berjalan sesuai dengan harapan atau tagihan dari kurikulum 2013.

Keterampilan guru menjadi lebih baik dalam mengimplementasikan membuat rencana program pembelajaran dan evaluasi sikap dan keterampilan sesuai dengan tuntutan kurikulum 2013 dibandingkan sebelumnya dan penggunaan instrumen penilaian proses berbasis evaluasi otentik dapat meningkatkan kognitif siswa ; (Susiani, Susilaningsih, Supardi, 2015) .Hal ini terkait dengan peningkatan pemahaman mengenai kurikulum secara keseluruhan dan keterampilan lain yang mendukung seperti analisis tagihan konten, instrumen evalausi proses dan hasil belajar dan pengembangannya serta model pembelajaran yang memenuhi standar proses termasuk pengkreasian model pembelajaran yang mendukung munculnya sikap dan keterampilan yang akan dinilai dalam proses pembelajaran. Rendahnya kompetensi gu ru dalam mengevaluasi sikap spiritual dan sosial telah berdampak negative terhadap prsetasi belajar siswa pada kompetensi inti karena hal tersebut merupakan focus utama dalam kurikulum berbasis karakter (Darmansyah. 2014; Setiawan et al, 2021). Dalam implementasi perlu lebih dalam lagi terkait dengan jenis dan tingkatan sikap dan keterampilan yang ditagih, artinya guru harus lebih dalam memhani dan mengkaji terkait dengan tagihan materi dan pengalaman belajar peserta didik serta teknik dan pelaksanaan asesmennya.

Pencapaian keterampilan guru dalam mendisan rubrik penilaian autentik sikap dan keterampilan sudah cukup baik namun perlu banyak latihan yang harus dikembangkan terutama akan lebih baik jika dilakukan ditingkat MGMP guru mata pelajaran yang ada di MA, sehingga akan lebih banyak manfaat bagi guru mata pelajaran yang bersangkutan. Namun demikian pengetahuan dan tekniknya harus dipahami terlebih dulu secara komprehensif, sehingga tidak terjadi kesalahan konsep dalam penggunaan model asesmen dan akan tepat sesuai dengan tagihan kompetensi inti dan dasar pada standar isi kurikulum untuk sikap dan keterampilan. Selain itu kekurangan dalam kesesuaian dancakupan antara tagihan sikap dan instrumen yang dikembangkan perlu dikaji lebih dalam agar terdapat kesesuaian antara tagihan dengan instrumen yang disusun dan pengalaman belajar peserta didik. Hal ini sangat penting karena terkait dengan pencapaian tujuan yang harus dicapai peserta didik setelah melaksanan pembelajaran dan rubrik asesmen seperti keterampilan proses sains pada pembelajaran IPA sangat baik sebagai penilaian pada aspek psikomotor siswa.( Wati dan Novianti. 2016) 
Pencapaian luaran dari pengabdian kepada guru MA Al Aziziyah Kapek, Gunungsari Lombok Barat rata-rata baik untuk setiap peserta dengan indikator guru telah memahami secara komprehensif mengenai kurikulum 2013 untuk setingkat MA; cukup terampil dalam menganalisis tingkat tagihan kurikulum 2013 yang menyangkut pengetahuan, sikap dan keterampilan; guru juga terampil dalam mengembangkan konten dan kompetensi dasar sikapmdan keterampilan kurikulum 2013 tingkat MA sesuai tagian terkait dengan dimensi kognitif dan pengetahuandan ranah sikap dan keterampilan, selain itu guru mampu menerapkan pemahaman keterampilanketerampilan terkait dengan pengembangan instrumen asesmen autentik sikap dan keterampilan dalam membuat perencanaan dan pelaksanaan pembelajaran serta pelaksanaan evaluasi proses dan hasil belajar. Selain itu instrumen penilaian proses penilaian berbasis evaluasi otentik yang berarti siswa dinilai dari permulaan, proses dan akhir pembelajaran; (Susiani, Susilaningsih, Supardi, 2015; Setiawan et al, 2016; Setiawan et al, 2020). Juga rubrik penilaian yang lengkap dibuat guru bisa mengungkap kualitas dan profil performance peserta didik. rubrik yang dapat dikembangkan seperti pada pelajaran Kimia meliputi kompetensi merangkai alat, menggunakan alat, melakukan eksperimen, mengelola zat sisa, mempresentasikan hasil eksperimen, dan penilaian terhadap Laporan eksperimen (Suryandari, 2013).

\section{KESIMPULAN}

Guru peserta workshop memahami secara komprehensif mengenai tagihan kurikulum nasional mencakup aspek keterampilan, sikap sosial, memiliki keterampilan dalam menyusun dan mengembangkan instrumen untuk pengukuran kompetensi keterampilan, sikap sosial dan dalam melaksanakan evaluasi proses hasil belajar siswa yang berupa keterampilan dan sikap sesuai dengan tuntutan kurikulum nasional.Hal tersebut akan bisa meningkatkan kualitas proses dan hasil belajar peserta didik di tingkat MA.

\section{UCAPAN TERIMA KASIH}

Ucapan terima kasih disampaikan kepada Bapak Rektor Universitas Mataram atas dukungan finansial untuk pelaksanaan pengabdian kepada masyrakat dan bapak ibu guru MA Al Azizyah Puteri Kapek Gunungsari atas kerja sama dan partisipasinya yang sangat baik dalam kegiatan pengabdian.

\section{DAFTAR PUSTAKA}

Darmansyah. 2014. Teknik Penilaian Sikap Spritual dan Sosial dalam Pendidikan Karakter di Sekolah Dasar 08 Surau Gadang Nanggalo. Jurnal Al-Ta'lim, Vol.21, Nomor 1.10-17.

Direktorat Pembinaan SMA Direktorat Jenderal Pendidikan Dasar dan Menengah Departemen Pendidikan dan Kebudayaan. 2017. Modul Penyususnan Soal Giher Ofreder Thinking Skills (HOTS). Jakarta: Direktorat Pembinaan SMA Direktorat Jenderal Pendidikan Dasar dan Menengah

Direktorat Pembinaan SMA Ditjen Pendidikan Dasar dan Menengah. 2017. Panduan Penilaian oleh Pendidik dan Satuan Pendidikan SMA. Jakarta: Direktorat Pembinaan SMA

Direktorat Pembinaan SMA Ditjen Pendidikan Dasar dan Menengah. 2017. Panduan Penilaian oleh Pendidik dan Satuan Pendidikan SMA. Jakarta: Direktorat Pembinaan SMA

https://www.researchgate.net/publication/318013627 KETERAMPILAN ABAD KE-21 KETERAMPILAN_YANG_DIAJARKAN_MELALUI_PEMBELAJARAN. Diakses Tanggal 4 Desember 2017Peraturan Menteri Pendidikan dan Kebudayaan Republik Indonesia Nomor 103 Tahun 2014 Tentang Pembelajaran Pada Pendidikan Dasar dan Pendidikan Menengah Pedoman Pelaksanaan Pembelajaran

Juhji. 2016. Peningkatan Keterampilan Proses Sains Siswa Melalui Pendekatan Inkuiri Terbimbing. Jurnal Penelitian dan Pembelajaran IPA. Vol. 2, (1), 58-70. 
Kementerian Pendidikan dan Kebudayaan (2012). Kurikulum 2013. Jakarta ; Kemendikbud

Kementerian Pendidikan dan Kebudayaan (2013). Kompetensi Dasar Sekolah Menengah Atas (SMA)/Madrasah Aliyah (MA). Jakarta ; Kemendikbud

Kementerian Pendidikan dan Kebudayaan Republik ndonesia. 2017. Modul Penguatan Pendidikan Karakter (PPK) Bagi Guru. Jakarta : Kementerian Pendidikan dan Kebudayaan Republik ndonesia.

Peraturan Menteri Pendidikan Dan Kebudayaan Nomor 64 Tahun 2013 Tentang Standar Isi Pendidikan Dasar Dan Menengah

Peraturan Menteri Pendidikan Dan Kebudayaan Nomor 69 Tahun 2013 Tentang Kerangka Dasar Dan Struktur Kurikulum Sekolah Menengah Atas/Madrasah Aliyah

Peraturan Menteri Pendidikan Dan Kebudayaan Republik Indonesia Nomor 66 Tahun 2013 Tentang Standar Penilaian Pendidikan

Peraturan Menteri Pendidikan dan Kebudayaan Republik Indonesia Nomor 104 Tahun 2014 Tentang Penilaian Hasil Belajar Oleh Pendidik Pada Pendidikan Dasar dan Pendidikan Menengah

Peraturan Menteri Pendidikan dan Kebudayaan Republik Indonesia Nomor 81a Tahun 2013 Tentang Implementasi Kurikulum

Peraturan Menteri Pendidikan dan Kebudayaan Republik Indonesia Nomor 103 Tahun 2014 Tentang Pembelajaran Pada Pendidikan Dasar dan Pendidikan Menengah Pedoman Pelaksanaan Pembelajaran

Peraturan Menteri Pendidikan dan Kebudayaan Republik Indonesia Nomor 104 Tahun 2014 Tentang Penilaian Hasil Belajar Oleh Pendidik Pada Pendidikan Dasar dan Pendidikan Menengah

Peraturan Pemerintah Republik Indonesia Nomor 32 Tahun 2013 Tentang Perubahan Atas Peraturan Pemerintah Nomor 19 Tahun 2005 Tentang Standar Nasional Pendidikan

Setiawan, H., Sa'dijah, C., \& Akbar, S. (2016). Pengembangan Instrumen Asesmen Autentik Kompeteensi Pada Ranah Keterampilan Untuk Pembelajaran Tematik di Sekolah 33 Dasar. Jurnal Pendidikan: Teori, Penelitian, dan Pengembangan. 2 (7) p. 874-882.

Setiawan, H., Khair, B. N., Ratnadi, R., Hakim, M., \& Istiningsih, S. (2020). Developing HOTS-Based Assessment Instrument for Primary Schools. In 1st Annual Conference on Education and Social Sciences (ACCESS 2019) (pp. 216-220). Atlantis Press. DOI: https://doi.org/10.2991/assehr.k.200827.054.

Setiawan, H., Nurhasanah, N., Umar, U., Nurmawanti, I., \& Fauzi, A. (2021). Instrument Development on Character Value Assessment at Grade IV Elementary School Students. In 2nd Annual Conference on Education and Social Science (ACCESS 2020) (pp. 470-475). Atlantis Press. DOI: https://doi.org/10.2991/assehr.k.210525.130.

Suryandari, E. T. 2013. Performance Assessment Sebagai Instrumen Penilaian Untuk Meningkatkan Ketrampulan Proses Pada Praktikum Kimia Dasar Di Tadris Kimia. Jurnal PHENOMENON, Volume 3 Nomor 2.

Susiani, E., Susilaningsih, E., Supardi, K. I. . 2015..Analisis Instrumen Penilaian Proses Berbasis Evaluasi Otentik Pada Pengukuran Keterampilan Proses Sains. Prosiding Seminar Nasional Kimia, ISBN: 978-602-0951-05-8 Jurusan Kimia FMIPA Universitas Negeri Surabaya, 3-4 Oktober 2015.B - 83

Undang-Undang Republik Indonesia Nomor 20 Tahun 2003 Tentang Sistem Pendidikan Nasional.

Wati, W. dan Novianti. 2016, Pengembangan Rubrik Asesmen Keterampilan Proses Sains Pada Pembelajaran IPA SMP. Jurnal Ilmiah Pendidikan Fisika Al-BiRuNi. 05 (1). 131-140. 